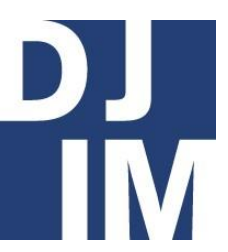

Volume 14

Spring

2018

djim.management.dal.ca |

\title{
The Effects of Social Media on Children
}

Tobbi Dyer

School of Information Management, Dalhousie University

\section{Abstract}

Social media and smartphones have become a part of our daily lives and children access the internet at increasingly younger ages. In Canada, approximately half of Grade 4 students go online regularly using portable devices and almost one-quarter own smart phones; by Grade $11,85 \%$ of students own smartphones.

The dangers for preteens (9-12) and young teenagers (13-15) include risks towards: personal safety, identity theft, privacy concerns, access to disturbing and inappropriate material, social isolation, and an increase in mental health concerns such as depression, anxiety, and poor sleep. There is also a significant risk of children becoming targets of cyberbullying or sexting. Some of these risks are a result of limited adult supervision and parents who are not adequately versed in online safety procedures.

However, social media can also provide children with positive interactions and stronger friendships both from their daily social circles and from like-minded individuals from various groups (LBGT, cultural, artistic, etc.). It can also improve access to diversity, increase inclusion, and reduce social isolation.

In order to benefit from the positive aspects of technology, children, along with their parents, need to be aware of the possible risks of social media and how to navigate them. Teaching technology has become a necessary part of a child's education. 


\section{Introduction}

Recent discourses on youth and young teenagers, particularly preteens $(9-12)$ and young teenagers $(13-15)$, are inundated with articles, memes, and anecdotes about the negative impacts of social media on youth. Regardless of one's opinion of social media, smartphones are becoming more ubiquitous and are introduced at younger ages (Influence Central.com, 2016). Smartphone use has risen dramatically in the past ten years and continues to rise (Statista.com, 2016); Canadian ownership of smartphones increased by $38 \%$ in only two years (Catalyst.ca, 2016) and the average age for American children to get their own smartphones is 10.3 years old (Influence Central.com, 2016). In Canada, approximately half of Grade 4 students go online regularly using portable devices and almost one-quarter own smart phones; this number increases to $85 \%$ for Grade 11 students (Media Smarts, 2015). Teens access and use a variety of social media platforms and websites (Facebook, Snap Chat, Instagram, etc.) with $92 \%$ using them daily (Lenhart, 2015). Perhaps the question to ask is not "Should children have access to social media?" which would be the equivalent of trying to put the proverbial genie back in the bottle, but rather, "What are the effects of social media and smartphones on children and what should we do about them?" This paper focuses primarily on preteens and young teenagers in Canada and the United States with some data incorporated from older teenagers.
As stated above, children and youth are heavy consumers of social media (Agnew, 2014). While data regarding usage varies, Dr. Michael Rich claims that children aged 8 to 18 use social media on their mobile devices for an average of almost eight hours a day (Agnew, 2014); American Academy of Pediatrics (2011) found in their poll that $22 \%$ of American teenagers admit to logging onto their favourite media sites more than ten times a day. It can be inferred that regardless of which study is consulted, children and youth spend a significant amount of time using social media. Most social media platforms, such as Facebook, require users to be at least 13 years old to create accounts. While heavy usage might seem to be an issue that affects teenagers but not children, approximately $75 \%$ of children between ten and twelve years old create social media accounts by falsifying their birthdates during registration (McDool, Powell, Roberts \& Taylor, 2016). Although preteen children are not officially recognized as users on these platforms, they are simply incognito and appearing as older users, which makes the full picture of preteen usage difficult to ascertain.

\section{Social Media Usage}

Such a shift in society, namely our frequent use of social media, must have an impact on our youth. In her article "Have Smartphones Destroyed a Generation?," Jean Twenge (2017) explains that, as a researcher concerned with generational differences, she noticed a drastic change in the behaviour and emotional states of 
teens starting in 2012, at which point over $50 \%$ of the American population owned smartphones (Catalyst.ca, 2016). Dr. Michael Rich, an associate professor of pediatrics at Harvard Medical School states:

We come at technology with a lot of preconceptions based on what we think is right and wrong, but ultimately this is not about values. We need to think about technology the way we think about our children's education. Let's use evidence to see how we are changed in positive or negative ways by these media and then make conscious use of them (Agnew, 2014, para. 3, my italics).

Preteens often join social media sites for similar reasons to adults: to maintain and strengthen friendships and to connect online with people who share common interests. They also join in response to peer pressure and in anticipation of dating opportunities, wanting a private venue to communicate with friends and seeking an avenue to explore aspects of their identities such as sexuality and ethnicity (Alim, 2016).

Clennett-Sirois (2014) asserts that teens are not attracted to the technology itself, but to the opportunity to interact with peers when there are fewer and fewer opportunities available to socialize in person. In a country that has recently seen a father investigated for letting his children take the city bus to school and given a mother a permanent child protection file because she let her children play in her The Effects of Social Media on Children fenced backyard, parents may be hesitant to let their children roam freely as they once did (Khoo, 2017; The Canadian Press, 2016). Participaction, in its 2015 Report Card, makes the strong statement that "we need to consider the possibility that rules and regulations designed to prevent injuries and reduce perceived liability consequences have become excessive, to the extent that they actually limit rather than promote children's physical activity and health" (Participaction, 2015, p. 7). With a lack of sufficient outdoor spaces along with tighter parental controls, children and young teens have embraced social media for many of their peer-to-peer interactions.

\section{Risks}

While there are social benefits for children accessing social media, and evidence that it might help mitigate the effects of loneliness, there are significant inherent dangers. Some of these risks occur because of access to unsupervised and unregulated content coupled with children's lack of awareness of privacy issues and their vulnerability to outside influences (American Academy of Pediatrics, 2011; McDool et al., 2016). While children used to access the internet from a family computer in a shared space, $38 \%$ of children now access the internet directly from their phones and $64 \%$ have access from their own laptops or tablets (Influence Central.com, 2016). It seems ironic in the current culture of helicopter parenting, which Bayless (2017) describes as "being involved in a child's life in a way that is over 
controlling, overprotecting, and over perfecting" (para.1) to the point that children do not have as many physical freedoms as they used to, that children and teens are often left to navigate the internet on their own. Although parents may believe they are keeping their children safe, in reality, a single stranger lurking in a playground is easier to spot than a multitude of strangers lurking in cyberspace who have potential online access to a child's own home through their media devices.

Recently, many parents naively put their trust in internet safety and allowed their children unsupervised access to YouTube children's videos; this resulted in children mistakenly accessing videos, tagged as child-friendly, which depicted explicit violence, sexual situations, or other inappropriate scenarios (Vaas, 2016). This content, which garnered income through ads, was deliberately created with the intention of bypassing the algorithms designed to filter adult content in the designated child-friendly zone (Vaas, 2016). This content featured familiar-looking characters that resembled those copyrighted by famous children's content producers such as Disney and Nickelodeon. A pseudo-Elsa from Disney's movie Frozen, for example, was seen being urinated on by a pseudo-Spiderman; at a quick glance, the content appeared authentic and escaped scrutiny (Vaas, 2016). While YouTube Kids has recognized the problem and is creating new policies and restrictions, internet safety cannot be guaranteed, even on a child4 friendly site. It stands to reason, then, than non-child-friendly sites would present even greater potential risks.

Some of these risks are due to the way that children and teenagers understand privacy and freely relinquish it. Laurence ClennettSirois (2014), in his review of "lt's Complicated: The Social Lives of Networked Teens, "discusses how a lack of privacy has been normalized for teens, especially with social networking sites having content publicly available as the default setting. He refers to this as "public-by-default, privatethrough-effort" (2014, para. 7) because children, or their parents, have to make the effort to change the settings to "friends only," which, even then, only provides partial protection of privacy. Parents contribute to the problem when they do not respect their children's privacy or even groom them to accept a lack of privacy as the norm. Laura Pinto, points out that the modern tradition of the Elf on the Shelf, in which parents tell their children that the stuffed toy is watching them and reporting their behaviour back to Santa Claus, is teaching children to accept in-home surveillance as normal (Holley, 2014). Even before this occurs, parents share a significant amount of information about their children online such as their child's name and date of birth along with other identifying information in social media posts (Steinberg, 2016). Without adjusting their cell phone camera settings, parents may also be inadvertently providing their child's location to anyone who can view the posted photos. While parents currently The Effects of Social Media on Children 
have the dubious legal right to share this information, the nature of the internet means that this information never goes away. It is easy to see why children tend not to value their online privacy, and this is concerning.

Stanley (2017) has brought to light the disturbing fact that "child ID fraud or theft will affect $25 \%$ of kids before turning 18 " (para. 3). Social media sites and online games and apps routinely ask children for personal information, including their dates of birth. With enough information about a child, identity thieves can create credit accounts under the child's name.. This theft can be problematic for children later in their lives; by the time they, or their parents, discover that they have a negative credit history, it might be too late to repair the damage. Most parents do not check their children's credit reports, but this may be a necessary precaution.

Without having many concerns for privacy, and with a desire to be liked and admired by their peers, young adolescents frequently post about themselves in a way that they think enhances people's perceptions of them (Lenhart, 2015 a). Girls in particular perceive the need to be attractive in a certain way and this can cause a great deal of anxiety (Agnew, 2014). In a Canadian study conducted by MediaSmarts (2017), young teens describe how they go online to socialize, but their intent is to look attractive to their peers. The worry about measuring up to perceived societal expectations helps to The Effects of Social Media on Children explain why spending time on social media may make children feel "less satisfied with all aspects of their lives, except for their friendships" (American Academy of Pediatrics, 2011, p. 801). Dr. Valerie Steeves, from the University of Ottawa explains that, "rather than opening up their world to new possibilities, online technologies are so enmeshed with mainstream media content that it is actually harder for girls to be authentic" (Agnew, 2014, para.10). Worrying about how others judge their appearance, and whether someone will unfriend them, negatively affects children's wellbeing by increasing children's anxiety.

Children's wellbeing is also affected by how much they compare their lives to the documented lives of others; with everyone trying to look good online, it is hard for youth to see that they may be comparing themselves to someone else's carefully constructed online persona (McDool et al., 2016). Children who spend too much time online reduce their involvement in other recreational activities which can have a negative effect on mood as well as on their quality of sleep (McDool et al., 2016). Further, preteens and teens who frequently engage with social networking sites exhibit signs of depression which may be due to the intensity of their online experiences (American Academy of Pediatrics, 2011); teens who are already struggling in life are at an increased risk (Clennett-Sirois, 2014). This increases the risk of social isolation and may amplify risky behaviours such as substance abuse, risky sexual activity, or 
other self-destructive behaviours (American Academy of Pediatrics, 2011).

A recent study from Korea University (Taylor, 2017) found that teenagers who had been diagnosed with internet or smartphone addiction had altered their brain chemistry. Scientists found that GABA, a neurotransmitter which helps to regulate vision, motor control, and anxiety, was significantly elevated in internetaddicted teens compared to non-addicted teens of the same age (with a mean age of 15.5), which led to increased drowsiness and anxiety (Taylor, 2017). Fortunately, participants who later received cognitive behaviour therapy saw these levels decrease or return to normal (Taylor, 2017). It has also been shown that the blue light emitted from smartphones and other devices can reduce levels of melatonin and interfere with the quality of children's sleep (Providence Health Team, 2017). Whether it is the nature of social media or the physical devices themselves, children are at risk of decreased mental health and increased psychological distress. This effect is specific to children and teenagers: university students who spend more than two hours per day using social media do not exhibit these negative effects (Ottawa Citizen, 2015).

\section{Cyberbullying}

Arguably the greatest risk of social media, and the one that has caught the attention of the news media, is cyberbullying. Cyberbullying is the use of online technology to deliberately and repetitively harm someone. This behaviour is facilitated by the large amounts of personal data posted online and the opportunity for interactions between users, which is in part a result of children and teens not adequately guarding their online privacy. Cyberbullying, due to the nature of the internet, can take place at any time and can easily and quickly spread to a large online audience. It can be difficult to trace the perpetrator or perpetrators and Smith et al. (2008) found that in about a third of cases, the victim does not know them (as cited in Alim, 2016). Unlike traditional bullying, the cyberbully can hide behind a fake account, which makes it nearly impossible for the victim to identify or face their perpetrators directly (Beale \& Hall, 2007).

Cyberbullying can take several forms. In a 2014 study,

$40 \%$ of students had received a mean comment through a SNS [social networking site], 37\% were victims of online gossip, $45 \%$ received prank [phone] calls, 30\% had a private message published without permission, whilst $26 \%$ had an embarrassing photo published without permission, $24 \%$ had been excluded from an online forum and 19\% had their online ID stolen (Alim, 2016, p. 70).

Compared to children in other age groups, children aged 12 to 15 received the most abusive emails and $25-28 \%$ of this age group experienced cyberbullying (Alim, 2016). These figures point to the enormity

The Effects of Social Media on Children 
of the problem and indicate that it is not a problem specific to older teenagers. Children who are not technically permitted to join social media sites are being bullied at an alarming rate. Not surprisingly, more marginalized teenagers, and those with low self-esteem, are more likely to be bullied and to be bullies themselves (Alim, 2016). Victims may experience difficulties interacting with their peer groups and may experience isolation, anxiety, and depression (Alim, 2016).

The most extreme form of cyberbullying involves sexting. Sexting is sending nude, semi-nude, or sexually explicit photos, and while legal between consensual adults it is, however, a risky activity because one has to trust that the other will not share the photo, even in the event of relationship changes. An estimated one-fifth of teens participate in sexting (American Academy of Pediatrics, 2011) and the risks can be greater than for adults. The Criminal Code of Canada prohibits the representation of children under 18 in a sexual manner and criminalizes the distribution of such material (Slane, 2013). While this is, understandably, designed to protect children from harm, children can also be convicted for sharing sexual images of themselves. An additional, and traumatizing, risk to children is a form of cyberbullying when the recipient of the image, or someone else who has access to it, shares it with other people without consent. Shared images can go viral, and can be accompanied by derogatory comments. Once this occurs, there is The Effects of Social Media on Children virtually no way to erase the accompanying digital footprint.

A tragic example of the effects of sexting and cyberbullying can been seen in the Canadian story of Rehtaeh Parsons, who died as a result of a suicide attempt in 2013 after a sexually explicit photo of her went viral. While details about what happened at a party in November, 2011 are unproven, the allegations are that Parsons was sexually assaulted by teenage boys while incapacitated by alcohol (McMillan, 2015). What is known is that a photo was taken of her throwing up out of a window while a boy was smiling at the camera and having sex with her (The Canadian Press, 2013). This photo was shared with other students at her high school who then re-shared it, which eventually made it go viral. This was followed by verbal assaults and harassment. As a result of the anguish and humiliation of being bullied and cyberbullied, Parsons died at only 17 years old after being taken off life support. Depression, self-harm, and suicide ideation are recognized as possible responses to enduring such forms of cyberbullying (American Academy of Pediatrics, 2011).

\section{Benefits}

Despite the significant risks inherent to children on social networking, we should not overlook the possible benefits, such as: opportunities for connecting with peers, enhancing learning opportunities, and personal development (Agnew, 2014). Preteens and teens need social connections and experiences: Rich (2014) states that 
"one of the great things the internet has done is create an environment where youth who feel isolated can create community" (Agnew, T. (2014, para. 4). Although it can appear disconcerting to adults to see children and teens interacting with their smartphones in a way that makes them appear anti-social, they are often, in fact, socializing with their friends. With fewer opportunities to interact in person, social networking can fill in this gap and help children maintain interpersonal connections (Clennett-Sirois, 2014). Children generally use social media to stay in touch with their existing real-world friends, and this extended form of communication helps to strengthen their bonds (Antheunis, Schouten, \& Krahmer, 2016). This text-based communication can also enhance communication and technical skills, which are beneficial to children's later success (American Academy of Pediatrics, 2011).

There are also benefits for children reaching outside their inner circles to make new friends, possibly from more diverse backgrounds. By identifying with likeminded individuals, children can participate in group discussions and collaborations for projects and thus enhance their feelings of self-worth (American Academy of Pediatrics, 2011). For example, Norton (2016) discusses the benefits to LGBT youth in accessing support groups and other information on social media. This is particularly important for youth who live in more homogenous communities, including many rural communities. Children may also 8 find others who share their artistic, literary, or other interests, which can reduce feelings of isolation. Improving their social bonds can guard against factors that put mental health at risk (Antheunis, Schouten \& Krahmer, 2016).

Children can also increase their bonds with family members and protect their physical safety by using their smartphones wisely. Jenson (2017) discusses how to implement a system of using code words with children and teens: if a child feels that they are in an unsafe situation, or they simply do not want to admit to their friends that they do not want to participate in an activity, they can send a predetermined code word to a family member. Even if this protocol has not been established, children can privately text their parents, and then delete the text if they chose, to ask for a ride home. This can be done without their peers being aware of the situation, as would likely happen if they had to make an actual phone call.

\section{Mitigating Risks}

In order to safely benefit from the positive effects of social media, while mitigating the potential risks, children have to be taught how to properly use this tool (Agnew, 2014). As a society, we understand the need to teach children to drive and generally require graduated licensing to allow them sufficient time to appropriately learn the skills required to drive safely. However, we often provide children with access to the greatest amount of information the world has ever seen

The Effects of Social Media on Children 
without much supervision or training. Steeves (2014) found that parents do, in fact, have an influence on their children's use of social media, and most children will approach them for support (as cited in Agnew, 2014). However, if children do not feel their parents have the technical knowledge, they may not seek their parents' or another adult's assistance (American Academy of Pediatrics, 2011). Further to this, children also may not think that their parents would know how to recognize a cyberbully or know what to do about it, reducing the likelihood that they will obtain help from them (Alim, 2016). To effectively assist children to use social media, and to gain their trust, parents and teachers need to make themselves aware of the technology, its uses, and its pitfalls. Privacy issues should be addressed at home, which requires parents to be aware of security features. Children are more inclined to consider internet safety if their parents are aware of possible risks and discuss safe usage with them (Alim, 2016). Educating themselves, then, may be one of the most effective ways for parents to help their children safely navigate the internet. There are even online quizzes for available for parents to learn about social networking sites and apps commonly used by children (Shum, 2017).

As well as potentially protecting their children from being vulnerable to online bullying, parents can also play a role in preventing their children from being bullies themselves. Preteens and teenagers are less likely to engage in cyberbullying, either The Effects of Social Media on Children by initiating it or by participating in existing smear campaigns, if they believe that adults will enforce negative consequences (Alim, 2016). Cyberbullies were also found to be heavy internet users and to participate in other risky behaviours (Alim, 2016). Limiting access to social media technology could potentially improve children's mental health and decreases both the risk of being cyberbullied as well as reducing participation in bullying behaviours (McDool et al., 2016).

Teachers, obviously, play a significant role in the lives of children and young teens. Awareness about how to safely navigate cyberspace needs to be a regular part of the curriculum as well part of the school's anti-bullying policy; successful prevention should include providing guidance to parents as well (Alim, 2016). Teachers should be aware, however, that group assemblies to address such issues are considered to be the least successful in meeting intended outcomes (Alim, 2016). Successful strategies have included learning how to identify the signs of cyberbullying, and bullying in general, and providing guidance to children on how to block bullies online and when to seek help. It is also important that parents and teachers recognize the risks and indicators of mental health concerns in children and to investigate possible links to bullying (Ottawa Citizen, 2015).

On a broader scale, online safeguards need to be in place to protect children. Facebook, for example, has recently 
announced that it will roll out a new app for children under 13 years old, called Messenger Kids (Isaac \& Singer, 2017) which allows parents to control their children's contact list and prevents children from being able to hide messages from their parents. While it is beneficial to Facebook to openly increase its client base, since children are likely using the platform anyway, providing a safer alternative available to them is a good start.

Improvements to apps and online applications can also be made. In a trial experiment, teenagers were shown digital messages that would be perceived as harmful to the recipient and asked if they would post them. The number of teenagers who indicated that they would be willing to post the text decreased significantly when an app popped up before-hand that asked if they were sure that they wanted to post something that would be hurtful to others. The conclusion in the trial was that children and teenagers don't have the level of impulse control required to prevent themselves from acting quickly without thinking, but when they were reminded of the possible negative outcomes, they chose to act appropriately (Alim, 2016). This is an encouraging finding and one can hope that this will be an option adopted by commonly used social networking sites.

The European Parliament introduced a Data Protection Bill in 2016, known as "The Right to be Forgotten," which recognizes that people have a right to the protection of their personal data. The right to freedom of expression is balanced by the level of harm someone might experience from having their data remaining online, and individuals can successfully request to have their data removed (Official Journal of the European Union, 2016). This type of legal protection, which is currently being introduced in the United Kingdom, could provide a great relief to people who have been cyberbullied or subjected to unauthorized sharing of their photos or other data. This would be particularly useful to children, either as victims of cyberbullying or for those who are living with the consequences of their own youthful media mistakes.

In 2013, in response to the Rehtaeh Parsons situation addressed above, Nova Scotia introduced an anti-bullying law to protect victims and hold perpetrators accountable: the Cyber-Safety Act (Laroche, 2017). It was struck down in 2015, however, because it was too broad and infringed on freedom of expression enshrined in Canada's Charter of Rights and Freedoms. New legislation, Bill 27, was introduced in 2017 and is expected to be passed into law in the spring of 2018 or later, which, as Justice Minister Mark Furey describes, is about "preventing and responding to the harms of sharing intimate images without consent, and cyberbullying... while at the same time, upholding and protecting our fundamental freedom of expression." Furthermore, Nova Scotia now has a definition for cyberbullying: an "electronic communication maliciously intended to cause harm ...or [with] reckless regard to the risk of harm" (Laroche, 2017, para. 4).

The Effects of Social Media on Children 
Simply having this recognized definition will make it more likely that appropriate charges can be laid because if something is not identified as an offence it is difficult to lay charges.

In addition to these changes in the law from the Rehtaeh Parsons case and in response to complaints made by Parsons' parents and other community members, an independent review of the handling of her case by the police and prosecution was completed in 2015 (Segal, 2015). A Progress Report investigating the status of the recommendations, which includes significant progress on their implementation, was completed in 2017. Successful initiatives or improvements include revising the sexual abuse and child abuse policies followed by the Halifax Regional Police Department (HRP). With input from people working in the field of sexual assault, the HRP has implemented a Trauma-Informed Approach when dealing with sexual assault survivors along with special statements that apply to children under 16 years old (Parsons was 15 years old at the time of the alleged assault). Halifax now has a Sex Crimes unit which combines the internet Child Exploitation Unit with the Sexual Assault Investigation Team.

Some other improvements identified in the Progress Report include prioritizing investigations that involve children, creating a cybercrime support unit, and evaluating the Education Act in its response to cyberbullying. Teaching staff and

The Effects of Social Media on Children principals in the Halifax Regional School Board have been provided with training to help them understand the new policies and how to address issues that occur either on or off school grounds; in addition, an antibullying coordinator and more mental health clinicians have been hired. It is hoped that these positive responses will help to prevent future tragedies due to cyberbullying.

\section{Conclusion}

Social media and the internet are here to stay so, as a society, we need to find ways to protect children from its harmful potential. The risks to their privacy, mental health and wellbeing, and vulnerability to cyberbullying and exploitation, needs to be mitigated through education to children as well as to their parents, caregivers, and educators. Children need to be taught effective procedures to protect their privacy and this should be appropriately modeled through good examples provided by the adults in their lives. Protective apps and software, along with appropriate restrictions, need to be applied to social networking sites that children access most often and laws need to be in place to protect victims from further harm or victimization by the legal system through ineffective or harmful approaches.

The benefits of social media should also be recognized. Children can deepen their existing friendships and create new ones, expand their access to diversity, increase their communication and technical skills, explore their own interests, and protect 
their physical safety when out of the home. These benefits are significant and worthwhile; the focus should be on maintaining and enhancing them while putting the identified safeguards in place for the benefit of everyone.

\section{Recommendations}

- Supervise children online

- Set limits to usage of online devices and social media

- Encourage children to play outside to improve mental health outcomes

- Learn about technology and cyberbullying and be approachable for children to ask questions

- Role model usage of appropriate privacy measures

- Teach children to protect their online privacy

- Teach children to identify cyberbullying

- Be clear that cyberbullying is not acceptable

- Incorporate protective apps when possible

- Check children's credit reports

- Press for laws to protect victims of cyberbullying

\section{References}

Agnew, T. (2014). Connected or disconnected? The Alberta Teachers' Association, 48 (18).
Retrieved from

https://www.teachers.ab.ca/Publicati ons/ATA\%20News/Volume-48-

2013-14/Number-

18/Pages/Connected-or-

disconnected.aspx

Alim, S. (2016). Cyberbullying in the world of teenagers and social media: A literature review. International Journal of Cyber Behavior, 6(2), 6895. Retrieved from https://www.researchgate.net/public ation/304536995_Cyberbullying_in_t he_World_of_Teenagers_and_Social_ Media_A_Literature_Review

American Academy of Pediatrics. (2011). Clinical report - The impact of social media on children, adolescents, and families. Retrieved from

http://web.mit.edu/writing/2012/Jul y_Summary_Readings/Impact_of_So cial_Media_on_Children_and_their_F amilies.pdf

Antheunis, M., Schouten, A. \& Krahmer, E. (2016). The role of networking sites in early adolescents' social lives. Journal of Early Adolescence, 36(3). Retrieved from http://journals.sagepub.com/doi/ab s/10.1177/0272431614564060

Bayless, K. (2017). What is helicopter parenting? Retrieved from http://www.parents.com/parenting/ The Effects of Social Media on Children 
better-parenting/what-is-

helicopter-parenting/

Beale, A. V., \& Hall, K. R. (2007).

Cyberbullying: What school administrators (and parents) can do. The Clearing House. 81(1) 8-

12. Retrieved from http://citeseerx.ist.psu.edu/viewdoc/ download?doi=10.1.1.459.8529\&rep $=$ rep 1 \&type $=$ pdf

Catalyst.ca. (2016). Smartphone behaviour in Canada and the implications for marketers in 2016. Retrieved from http://catalyst.ca/2016-canadiansmartphone-behaviour/

Clennett-Sirois, L. (2014). [Review of the book It's complicated: The social lives of networked teens, by $D$ Boyd]. Canadian Journal of Communication, 39, 663-665. Retrieved from http://www.cjconline.ca/index.php/journal/article/v iew/2917/2500

Holley, P. (2014, December 16). The elf on the shelf is preparing your child to live in a future police state, professor warns. The Washington Post. Retrieved from https://www.washingtonpost.com/n ews/arts-andentertainment/wp/2014/12/16/theelf-on-the-shelf-is-preparing-yourchild-to-live-in-a-future-police-

The Effects of Social Media on Children state-professorsays/?utm_term $=. e 5237287 \mathrm{c} 23 \mathrm{~b}$

Influence Central.com. (2016). Kids \& tech: The evolution of today's digital natives. Retrieved from http://influence-central.com/kidstech-the-evolution-of-todaysdigital-natives/

Isaac, M., \& Singer, N., (2017, December 4). New Facebook app for children ignites debate among families. The New York Times. Retrieved from https://www.nytimes.com/2017/12/ 04/technology/facebookmessenger-kids.html

Jenson. K. (2017). Code words: Giving kids an easy (and safe) way out. Retrieved from https://protectyoungminds.org/201 7/03/30/code-words-give-easyway-out/

Khoo, I. (2017, September 6). Dad challenges ruling that school-age kids can't ride transit alone. The Huffington Post. Retrieved from http://www.huffingtonpost.ca/2017/ 09/06/father-kids-taking-transitvancouver_a_23198830/

Laroche, J. (2017, October 5). N.S. introduces new cyberbullying law it hopes passes constitutional muster. CBC News. Retrieved from http://www.cbc.ca/news/canada/no 
va-scotia/cyber-bullying-law-bill-nslegislature-rehtaeh-parsons-

1.4340758

Lenhart, A. (2015). Chapter 4: Social media and friendships. Pew Research Center. Retrieved from http://www.pewinternet.org/2015/0 8/06/chapter-4-social-media-andfriendships/

McDool, E., Powell, P., Roberts, J. \& Taylor, K. (2016). Social media use and children's wellbeing. University of Sheffield, UK. Retrieved from https://www.sheffield.ac.uk/polopol y_fs/1.669622!/file/paper_2016011.p df

McMillan, E. (2015, October 8). Rehtaeh Parsons case review finds system "failed." CBC News. Retrieved from http://www.cbc.ca/news/canada/no va-scotia/rehtaeh-parsons-casereview-1.3262111

MediaSmarts. (2014). Young Canadians in a wired world. Retrieved from http://mediasmarts.ca/sites/medias marts/files/pdfs/publicationreport/full/YCWWIII_Life_Online_Full Report.pdf

Norton, S. (2016). Exploring positives and negatives of social media and their effects on LGBT youth in America. (Masters dissertation). Retrieved from https://search.proquest.com/openvi ew/ca5234692f1 efd7927866b874c9 c5970/1?pqorigsite $=$ gscholar $\& \mathrm{cbl}=18750 \&$ diss $=\mathrm{y}$

Official Journal of the European Union. (2016). Regulation (EU) 2016/679 of the European Parliament and of the Council. Brussels. Retrieved from http://ec.europa.eu/justice/dataprotection/reform/files/regulation_o j_en.pdf

Ottawa Citizen. (2015, August 8). Study links teens who spend at least two hours per day on social media to suicidal thoughts, poor mental health. National Post. Retrieved from http://nationalpost.com/news/cana da/study-links-teens-that-spend-atleast-two-hours-per-day-on-socialmedia-to-suicidal-thoughts-poormental-health

Participaction. (2015). The biggest risk is keeping kids indoors. The ParticipACTION Report Card on Physical Activity for Children and Youth. Retrieved from https://www.participaction.com/site s/default/files/downloads/Participac tion-2015ReportCardFullReport_4.pdf

Providence Health Team. (2017, May 15). How blue light affects your The Effects of Social Media on Children 
children's sleep. Retrieved from http://blog.providence.org/archive/ how-blue-light-affects-yourchildren-s-sleep

Segal, M. (2015). Independent review of the police and prosecution response to the Rehtaeh Parsons case. Toronto. Retrieved from https://novascotia.ca/segalreport/Pa rsons-Independent-Review.pdf

Shum, N. (2017, September 7). Internet safety quiz: How much do you know? PTO Today. Retrieved from https://www.ptotoday.com/ptotoday-articles/article/8109-internetsafety-quiz-how-much-do-youknow

Slane, A. (2013). Sexting and the law in Canada. Canadian Journal of Human Sexuality, 22(3). Retrieved from https://papers.ssrn.com/sol3/papers .cfm?abstract_id $=2836033$

Stanley, M. (2017). Child identity theft: $A$ guide for parents. Retrieved from https://www.forbes.com/sites/morg anstanley/2017/08/02/childidentity-theft-a-guide-forparents/\#7f2103213177

Statista.com. (2016). Number of smartphones sold to end users worldwide from 2007 to 2016 in

The Effects of Social Media on Children million units. Retrieved from https://www.statista.com/statistics/2 63437/global-smartphone-sales-toend-users-since-2007/

Steinberg, S. (2016). Sharenting: Children's privacy in the age of social media. University of Florida Levin College of Law Research Paper. Retrieved from https://ssrn.com/abstract=2711442

Steeves, V. (2015). Young Canadians in a wired world. Media Smarts. Retrieved from http://mediasmarts.ca/sites/medias marts/files/publicationreport/full/ycwwiii_trends_recomme ndations_fullreport.pdf

Taylor, S. (2017). Smartphone addiction may cause brain imbalance. Radiology Society of North America. Retrieved from https://rsna2017.rsna.org/dailybullet in/index.cfm?pg=17fri08

The Canadian Press. (2013, August 13). A chronology of the Rehtaeh Parsons case. Global News. Retrieved from https://globalnews.ca/news/777152 /a-chronology-of-the-rehtaehparsons-case/

The Canadian Press. (2016, April 22). Child services grills Winnipeg mom after she let her kids play alone in their 
fenced-in backyard. National Post.

Retrieved from

http://nationalpost.com/news/cana da/child-services-grills-winnipegmom-after-she-let-her-kids-playalone-in-their-fenced-in-backyard

Twenge, J. (2017, September). Have smartphones destroyed a generation? The Atlantic Daily. Retrieved from https://www.theatlantic.com/magazi ne/archive/2017/09/has-thesmartphone-destroyed-ageneration/534198/

Vaas, L. (2017). YouTube to crack down on inappropriate videos targeting kids. Retrieved from https://nakedsecurity.sophos.com/2 017/11/13/youtube-to-crack-downon-inappropriate-videos-targetingkids/ 